\title{
Reseña
}

\section{Para una crítica de la democracia en América Latina*}

\section{Por: Santiago Tafernaberry Cicimbra**}

* Nicolás Lynch

Buenos Aires, CLACSO, 2020,

$136 \mathrm{pp}$

ISBN: 978-987-722-714-7

** Estudiante de la Licenciatura en Trabajo Social. Departamento de Ciencias Sociales, Cenur Litoral Norte, Universidad de la República, sede Salto. \santitafernaberry03@ gmail.com https://orcid.org/0000-00019839-1051
La idea que atraviesa todo el libro es la de los múltiples significados y formas que tiene la democracia para desarrollarse en América Latina. Es relevante analizar cómo las sociedades construyen su ideal de democracia y trabajan de forma unificada para llevarlo adelante.

¿Cuáles son los desafíos que presentan las democracias actuales en América Latina? Esta pregunta es clave para aproximarse al trabajo. Nicolás Lynch busca comprender la democracia de una manera integral y compleja. No solo se enfoca en definirla teóricamente y problematizar cómo la viven los seres humanos, sino que busca interpretarla desde las distintas dimensiones que interactúan con ella, es decir, la esfera social, económica, cultural y política.

El autor elabora un texto interesante y apropiado en el que amplía su mirada sobre la democracia actual y utiliza el factor histórico para comprender las transformaciones que la han llevado a ser lo que es hoy en día. Si bien los cambios le aportan nuevos enfoques y ampliación de derechos, también hay que interpretarla desde una perspectiva crítica para determinar los aspectos por fortalecer.

Es fantástica la capacidad del autor para reflexionar sobre un suceso que se está desarrollando en nuestros días. Desde esta perspectiva, Edgardo Mocca (2018) sostiene que los fenómenos políticos no son algo aislado o sin importancia para quien los anal iza, comprende y estudia, sino que la capacidad del investigadoro del analista se ven cuando sus propósitos forman parte de la realidad que pretende analizar. Estas cuestiones dejan en claro que los intelectuales o pensadores nunca son neutrales; siempre adoptan posturas, argumentan y reflexionan de acuerdo a su trayectoria académica, política y personal. 
En la actualidad la democracia ha cambiado y la sociedad la ha adaptado a sus necesidades. Los seres humanos entienden que es fundamental democratizar nuevos aspectos de la vida; es posible desarrollar estrategias que busquen reivindicar derechos humanos a través de la lucha social y colectiva. Si formamos sujetos políticos, tendremos la seguridad de que las minorías y la sociedad en general tendrán respaldo para la defensa de sus derechos.

Los movimientos sociales son de utilidad para poner en la agenda pública las problemáticas social es que afrontan las personas en su vida cotidiana. Para que las sociedades tengan una mejor democracia, los Estados se enfrentan al desafío de potenciar los espacios participativos, generar diálogos y puentes con la academia y con los movimientos sociales, a fin de que, juntos, sea posible unificar fuerzas e intentar minimizar los efectos de la pobreza, la desigualdad social, la exclusión social, la precarización laboral, el desempleo y otras problemáticas sociales que se agudizan en la actualidad.

No es posible desconocer que los movimientos sociales se enfrentan a enemigos poderosos como el capitalismo, el patriarcado y el colonialismo. Por ende, la lucha colectiva es trascendental para brindar respuestas a las personas y reivindicar la democracia y los derechos que esta ofrece. Ante gobiernos neoliberal es y autoritarios que en América Latina han intentado implementar golpes de Estado, dictaduras, eliminar conquistas y quitar protagonismo a los colectivos, los movimientos sociales se convierten en movimientos políticos para generar transformaciones sociales.

Tomando los aportes de Naomi Klein (2007), el autor considera que el momento oportuno para imponer ideas radicales de libre mercado es el período subsiguiente a un gran shock, y este puede ser cualquier situación que afecte la vida de los seres humanos, como una crisis económica o la pandemia que actualmente estamos transitando. Se observa quela doctrina del shock es netamente psicológica, ya que busca convencer y adoctrinar a las personas para que acepten dichas reformas como imprescindibles.

Considero que la pandemia ha generado temor al contagio, incertidumbre y agudización de las problemáticas sociales. Ante el miedo a contagiarse, muchas personas han reproducido discursos como «quédate en casa». De acuerdo con lo planteado por Naomi Klein, este acontecimiento puede ser eficiente para implementar medidas y reformas neoliberales que favorecen a unos pocos y perjudican a la mayoría, las cuales muy pocas veces son puestas en discusión y suelen aceptarse fácilmente. Estas reformas han provocado desigualdades social es, pobreza, vulnerabilidad y permanencia del sistema capitalista.

Luego de una minuciosa lectura del libro, los principal es temas que de allí se desprenden son: la intención de conservación que presentan el capitalismo, el colonialismo y el patriarcado como sistemas dominantes y hegemónicos; la necesidad de crear mecanismos que permitan acentuar las transformaciones sociales a partir de la construcción de actores políticos que entiendan la premura de cambiar situaciones de opresión y 
desigualdad social y de continuar democratizando nuevas prácticas en pos de generar inclusión, igualdad, dignidad, equidad, participación socialy emancipación.

En los países de América Latina se encuentran invisibilizados en menor o mayor medida los problemas estructurales e históricos que debemos atacar desde las raíces para transformarlos y hacerlos menos cruel es paralos seres humanos. Fernand Braudel (1982) considera que los problemas deben solucionarse desdelo profundo, donde será necesario organizar el poder para encontrar las raíces de nuestra historicidad.

El autor nos lleva a cuestionarnos sobre qué acciones desarrollamos para ampliar la democracia en nuestras sociedades. Desde que asumieron los gobiernos progresistas por la vía el ectoral en América Latina, algunos Estados impulsaron procesos institucionales que buscaban generar cercanía con la sociedad civil - un claro ejemplo es el presupuesto participativo-, y desde la sociedad civil han emergido propuestas no institucionales, como protestas, convocatorias, marchas o reivindicaciones. América Latina está llena de experiencias, tanto estatales como de la sociedad civil, que demandan mayor participación de las personas, que estas puedan tomar decisiones sobre asuntos que las afectan directa o indirectamente, y que estos procesos conduzcan a unificar a las sociedades y establecer diálogos continuos entre representantes y representados.

Con sus objetivos de defender a las minorías, brindarles oportunidades, espacios, derechos y conseguir que estos grupos puedan integrarse en la sociedad, saliendo de ese contexto de pobreza y vulnerabilidad en el cual están insertos, históricamente los denominados gobiernos nacionales-populares fueron instrumentos para alcanzar mayores niveles de democratización en los países de América Latina. Nicolás Lynch (2020) sostiene que es necesario luchar para eliminar las desigualdades sociales, haciendo de la justicia social una cuestión política.

La democracia en América Latina ha sufrido múltiples transformaciones para hacerla inclusiva e integradora de las particularidades y diferencias entre los seres humanos. Un aspecto clave para concretar estos cambios fueron los líderes populares que entendían que las problemáticas social es se debían atacar desde una perspectiva colectiva y unificada, y ante ello impulsar políticas sociales universal es, en las que lo importante fuera el bienestar y la calidad de vida de las personas.

Por lo tanto, estas reflexiones no son finales sino insumos para continuar generando nuevos conocimientos a través de preguntas: ¿Cuáles son los nuevos desafíos para los gobiernos progresistas? ¿Cómo vencer al capitalismo, el patriarcado y el colonialismo? ¿Cómo expandir una perspectiva crítica para analizar la democracia en América Latina? Estas preguntas son insumos para caminar hacia sociedades horizontales, participativas, equitativas, inclusivas y diversas. Ese es el desafío. 


\section{Referencias bibliográficas}

Braudel, F. (1982). La historia y las ciencias sociales (pp. 60-106). Madrid: Alianza.

Klein, N. (2007). The shock doctrine: The rise of disaster capitalism. Nueva York: Metropolitan Books.

Lynch, N. (2020). Para una crítica de la democracia en América Latina. Buenos Aires: CLACSO.

Mocca, E. (2018). El antagonismo argentino: Problema insoluble del neoliberalismo y causa de la crisis del gobierno de Mauricio Macri. Buenos Aires: Colihue. 